Article

\title{
Phenotypic Variability and Genetic Diversity in a Pinus koraiensis Clonal Trial in Northeastern China
}

\author{
David Kombi Kaviriri ${ }^{1,2,3}{ }^{\circledR}$, Qinhui Zhang ${ }^{1}$, Xinxin Zhang ${ }^{1}$, Luping Jiang ${ }^{1}$, Jinpeng Zhang ${ }^{4}$, \\ Jingyuan Wang ${ }^{4}$, Damase P. Khasa ${ }^{5}$, Xiangling You ${ }^{1}$ and Xiyang Zhao ${ }^{1, * \mathbb{D}}$ \\ 1 State Key Laboratory of Tree Genetics and Breeding, Northeast Forestry University, Harbin 150040, China; \\ davidkaviriri@yahoo.fr (D.K.K.); zqh19950201@163.com (Q.Z.); zhangxinxin126@126.com (X.Z.); \\ 15737928328@163.com (L.J.); yxiangling@yahoo.com (X.Y.) \\ 2 Department of Natural Resources Management, Faculty of Agricultural Sciences, University of Kinshasa, \\ P.O. Box 117, Kinshasa XI 023, Congo \\ 3 Department of Forestry, Faculty of Agricultural Sciences, Semuliki Official University, Beni 48, Congo \\ 4 Forest Cultivation Center, Linjiang Forestry Bureau of Jilin, Linjiang 134600, China; llzyckly@126.com (J.Z.); \\ wjY7909@126.com (J.W.) \\ 5 Canada Research Chair in Forest and Environmental Genomics, Centre for Forest Research and Institute for \\ Integrative Biology and Systems, Université Laval, Quebec, QC GiV 0A6, Canada; \\ damase.khasa@ibis.ulaval.ca \\ * Correspondence: zhaoxyphd@163.com; Tel.: +86-0451-8219-2225
}

Received: 14 April 2020; Accepted: 15 June 2020; Published: 19 June 2020

check for updates

\begin{abstract}
Combining phenotypic and genetic characteristics in a genetic variation study is of paramount importance to effectively orient the selection of producers' elite trees in a seed orchard. In total, 28 phenotypic characteristics and 16 microsatellite loci were used to analyze the clonal genetic variation, to characterize the genetic diversity, and to refine the genetic classifications of 110 Pinus koraiensis clones grown in the Naozhi orchard in northeastern China. All clones were significantly different in most traits. Most of the phenotypic characteristics showed great genetic variation among clones, while the genotypic differentiation was weak between the selection sites of clones. The SSR markers showed a relatively high level of genetic diversity $(\mathrm{Na}=4.67 \pm 0.43$, $\mathrm{Ne}=2.916 \pm 0.18, \mathrm{I}=1.15 \pm 0.07, \mathrm{Ho}=0.69 \pm 0.04, \mathrm{He}=0.62 \pm 0.02$, and mean polymorphic information content (PIC) of 0.574 ), with higher heterozygosity as an indication of a lower probability of inbreeding events in the orchard. Despite weak correlation coefficients between dissimilarity matrices $(\mathrm{r}(\mathrm{A} / \mathrm{B})$, range equal to $0.022, p$-value $<0.001)$, the genetic and phenotypic classifications congruently subdivided all the clones into three major groups. The patterns of phenotypic trait variations and genetic diversity are valuable to effectively select materials in breeding programs of P. koraiensis.
\end{abstract}

Keywords: clone classification; genetic diversity; Pinus koraiensis; phenotypic variation; microsatellite markers

\section{Introduction}

Pinus koraiensis Sieb. et Zucc (Korean pine) is an important economic timber species that dominates the mixed broadleaf-conifer forests in northeastern China [1]. Korean pine can reach a stem height of $30 \mathrm{~m}$ and a diameter of $150 \mathrm{~cm}$ at breast height [2]. P. koraiensis naturally occurs in a reduced area within northeastern China, north of North Korea, central Japan, and southeastern Russia [3]. It is widely appreciated for its use in internal and external construction, particularly due to the high quality of its 
wood [3]. The nuts of this species are also used for a variety of nutritional products and therapeutics [4]. Because of its various economic benefits, along with its increasingly recognized environmental roles in $\mathrm{CO}_{2}$ sequestration, water regulation and soil protection for plantations on slopes [5], the Korean pine has been extensively recommended for afforestation and reforestation projects [6]. Currently, artificial Korean pine forests are grown throughout northeastern Chinese provinces [7].

The $P$. koraiensis breeding program is considered among the oldest and largest forest tree improvement programs in China. Phenotypically superior Korean pine trees have been selected from natural forestlands and have been established in seed orchards since the early 1960s [8]. Many studies have evaluated the outcome of the Korean pine breeding program, and numerous elite tree lines have been selected based on phenotypic and genetic variability in growth, wood, fruit, seed and nutrient content within clonal, half-sib and full-sib P. Koraiensis populations $[9,10]$. Improved clones of $P$. koraiensis spp. were selected based only on their growth traits or wood properties to meet the demand for timber over the past several years [11]. However, with the official decree in 2016 against the cutting of natural forests, more attention has been paid to seeds and cones of P. koraiensis $[4,12]$. Considering only the seed yield, China is reported to have generated more than \$250 million USD annually from pine nuts [13].

Although the selection of superior P. koraiensis trees and elite materials has traditionally been based on phenotypic characteristics, many genetic markers have been developed to characterize Korean pine genetic diversity [14,15] and assess clone fingerprints, paternity analysis, and pedigree reconstruction for breeding populations in tree improvement programs $[16,17]$. However, no study to date has linked the genetic variation in Korean pine with phenotypic characteristics and genetic markers.

Species genetic diversity highlights a pivotal role for trees under breeding programs to develop well-adapted tree varieties and heighten genetic gain for a multitude of useful traits [18,19]. To achieve genetic improvements, the breeder needs to maintain a certain amount of genetic diversity [20]. Maintaining high genetic diversity is a fundamental concern for breeders during recurrent selection operations. In fact, on one hand, breeders need to increase genetic gain by reducing the population size to only the elite individuals; on the other hand, breeders can increase the population's adaptability through genetic diversity by guarding a large number of different genotypes [21,22].

The genetic diversity parameters measure the degree of resemblance and difference in the genetic characteristics of individuals or the population and could therefore guide assisted hybridization processes by preventing associations of genetically closed individuals [23]. Much research has shown a greater performance in the biomass, speed of development, and fertility in progeny compared to those of both parents defined as heterosis [24]. This has resulted from the heterozygosity (diversity) and dominance effect of crossed parents [25]. Reduced heterosis may result from the disharmonious functioning of alleles [26], but the heterosis effect will be greater when the crossed entities are genetically different [27].

The pairwise relatedness measurement displays a significant role in the genetic resource conservation. For instance, in a seed orchard, substantial effort would be made to ensure that close relative trees are not crossed to reduce inbreeding and reduce the loss of genetic variation by random genetic drift [28]. Using molecular markers, estimating the genetic relatedness between individuals can reveal correlations between genetic and phenotypic characteristics [29]. Microsatellite markers display high rates of polymorphism, good reproducibility, codominant inheritance and regular distribution in the coding and noncoding regions of the plant genome [30]. Because of that, microsatellites are recognized as the most efficient genetic markers for assessing genetic diversity and population genetic structure and for investigating relatedness between individuals [29].

The present study analyzed the phenotypic variability and genetic diversity of different clones (parent trees) and sought to establish their genetic similarities to lay the foundation for understanding vigor in offspring from possible combinations of different clone genotypes. In total, 28 phenotypic traits (11 growth traits; three wood traits; and 14 fruit, seed, and nut characteristics) were investigated and analyzed using 38-year-old P. koraiensis clones in the Naozhi seed orchard. The data of 16 codominant 
microsatellites were combined to compare genetic variation with phenotypic variability. Hence, the objectives of this study were to (i) analyze the clonal phenotypic and genetic variation, (ii) compare and combine phenotypic and genetic distances to assess the genetic diversity of $P$. koraiensis, and (iii) establish the genetic relationship among clones/genotypic relatedness based on phenotypic and molecular markers.

\section{Materials and Methods}

\subsection{Study Area and Plant Materials}

Data were collected from the Naozhi forest seed orchard located on the western hillside of Changbai Mountain in Linjiang city, Jilin Province, northeastern China $\left(41^{\circ} 05^{\prime} \mathrm{N}, 126^{\circ} 06^{\prime} \mathrm{E}\right)$. The P. koraiensis forest and broad-leaved mixed forest are typical forest vegetations of this region and occur at an altitudinal range between $700 \mathrm{~m}$ and $1100 \mathrm{~m}$. The area experiences a continental monsoon climate type. In this region, the summer temperature is moderate because of the altitudinal gradient and rains, while the winter is long and cold. The average annual temperature and average annual rainfall range between $4{ }^{\circ} \mathrm{C}$ and $6{ }^{\circ} \mathrm{C}$ and $750 \mathrm{~mm}$ to $1000 \mathrm{~mm}$, respectively. The frost-free period is 135 days. The soil type corresponds to the Albi-Boric Argo sols, according to U.S. soil taxonomy [31], and is dominated by dark brown soil of more than $40 \mathrm{~cm}$ thick, with a portion comprised of important textural constituents: sand (15.13\%), silt (63.31\%) and clay (21.56\%) [32].

Tree measurements and plant materials were collected from surviving ramets of the 110 P. koraiensis clones (PK1-PK110). In 1979, superior Korean pine trees (based on their size) were selected from the natural P. koraiensis forestland in Linjiang, Jilin Province $\left(41^{\circ} 55^{\prime} 33.86^{\prime \prime} \mathrm{N}, 127^{\circ} 01^{\prime} 33.26^{\prime \prime} \mathrm{E}\right)(\mathrm{PKJ}-1$ to PKJ-90) and Liaoning Caohe, Liaoning province ( $40^{\circ} 52^{\prime} 17.24^{\prime \prime} \mathrm{N}, 123^{\circ} 54^{\prime} 13.63^{\prime \prime}$ E) (PKL-91 to PKL-110). These clones were grafted in the year following their collection, and plantations were established with four-year-old seedlings in the spring of 1984. The experimental design consisted of a complete randomised block design using single tree-plots, with 10 blocks containing 110 different clones, and ramets of each clone were planted at inter plant and row spacing of $7.0 \mathrm{~m} \times 7.0 \mathrm{~m}$.

\subsection{Growth, Wood, and Fruit Trait Measurements}

The following traits were measured on living ramets in July 2018: 11 growth traits, including tree height $(\mathrm{Ht})$, basal diameter (BD), diameter at breast height (DBH), diameter at 3-m height (DIAM-3m), bark thickness (BTH), stem volume (Vol.), stem straightness degree (SSD), branch angle (BA), crown breadth $(\mathrm{CB})$, crown height $(\mathrm{CH})$, and branch number $(\mathrm{BNN})$; three wood traits, including wood density (WD), fiber length (FL), and fiber width (FWd); and 14 cone, seed, and nut traits comprising cone number $(\mathrm{CN})$, cone length $(\mathrm{CL})$, cone width $(\mathrm{CWd})$, cone weight $(\mathrm{CW})$, layer number $(\mathrm{LN})$, seed number per cone (SNC), seed length (SL), seed width (SWd), seed weight (SW), nut length (NL), nut width (NWd), nut weight (NW), seed coat thickness (SCTH), and 1000 seed weight (1000 SW).

$\mathrm{Ht}$ and $\mathrm{CH}$ were measured with a meter ruler; $\mathrm{BD}, \mathrm{DBH}$, and DIAM3 were measured using a caliper; SSD was estimated and squared before calculation using the method of [33]. CB was calculated by averaging the values of the north-south and east-west crown width, and $\mathrm{CH}$ was obtained by subtracting the tree height at the first branch from the total tree height. The stem volume (Vol.) of each tree was computed according to the formula of Louppe [34] using a form coefficient of coniferous trees of 0.41 , as shown in the following equation: Vol. $=\mathrm{DBH}^{2} \times \mathrm{Ht} \times \pi \times \mathrm{fc} / 40000,(\pi=3.14$ and $\left.\mathrm{fc}_{\mathrm{C}}=0.41\right)$.

From each clone, wood cores were collected from all ramets, following the altitudinal south-north orientation at breast height level $(1.3 \mathrm{~m})$ using an increment borer and were then taken to the laboratory for investigations of their wood properties. The WD and fiber dimensions (FL and FW) were measured according to the method used by Yin et al. [35].

For fruit-related traits, all the cones were collected from each ramet after reaching maturity. Cones were counted $(\mathrm{CN})$ and directly weighed $(\mathrm{CW})$. To obtain a balanced number of cones per clone, 
cones from previous years (2014 to 2018) were taken into account, and the calculated average was used in the analysis. Meanwhile, the cone size seeds and nuts were measured only in the year 2018. CL and CWd (perpendicularly at the broadest part) were measured with a digital caliper. After taking dimensions and weights from cones, all the seeds were removed from cones, and the number of seeds per cone per ramet was counted; the average value was used as cone SNC. To calculate the $1000 \mathrm{SW}$, seeds from different ramets were mixed. Then, 400 seeds were randomly chosen and divided into four equal parts to serve as replicates. Each group of 100 seeds was weighed, and the thousand seed weight was obtained by extrapolation from the weight of 100 seeds. Fifty seeds from each clone were randomly chosen to determine seed characteristics and measure SL, SWd, and SW. Finally, nuts were extracted from measured seeds, and NL, NWd and NW were assessed. SCTH was measured 10 times from different sides for each seed using a Vernier caliper, and the average values were used.

\subsection{DNA Extraction and Simple Sequence Repeats (SSR) Analysis}

Fresh needles were collected from each clone from an accessible branch. The collected needles were directly chilled under ice, transported to the laboratory and stored in a freezer at $-80{ }^{\circ} \mathrm{C}$ for subsequent DNA analysis. Genomic DNA was extracted from P. koraiensis needles using a modified cetyltrimethylammonium bromide (CTAB) method, according to Allen et al. [36]. The DNA concentration and quality were tested using $1 \%$ agarose gel electrophoresis and a gel imaging system (Tanon-2500R, Tanon Science \& Technology Co., Ltd., Shanghai, China). Sixteen published Simple Sequence Repeats (SSR) primer pairs were selected from previous studies ([16,37]) and used to perform PCR analysis (Table S1).

DNA amplification (PCR reaction) was carried out in a total volume of $25 \mu \mathrm{L}$ containing $2.5 \mu \mathrm{L}$ of ExTaq buffer, $2 \mu \mathrm{L}$ of dNTP $(2.5 \mathrm{mM}), 1 \mu \mathrm{L}$ of MIX primer, $1 \mu \mathrm{L}$ of plant DNA, $0.2 \mu \mathrm{L}$ of ExTaq (Takara, Beijing, China), and $18.3 \mu \mathrm{L}$ of $\mathrm{H}_{2} \mathrm{O}$. The PCR was performed according to the following cycling program: denaturation step at $95^{\circ} \mathrm{C}$ for $2 \mathrm{~min}$; followed by 35 cycles of $95^{\circ} \mathrm{C}$ for $20 \mathrm{~s}$, annealing at $53 \sim 58{ }^{\circ} \mathrm{C}$ for $20 \mathrm{~s}$ (with different annealing temperatures for each primer pair), and $72{ }^{\circ} \mathrm{C}$ for $20 \mathrm{~s}$ for extension; and a final extension at $72{ }^{\circ} \mathrm{C}$ for $10 \mathrm{~min}$. The reactions were then kept at $12^{\circ} \mathrm{C}$. All forward primer sequence markers were labeled with four fluorescent dyes: HEX (green), FAM (blue), TAMRA (yellow), and ROX (red). Amplified SSR fragments were analyzed using a capillary electrophoresis sequencer ABI 3730 XL DNA analyzer (Applied Biosystems, Foster City, CA, USA). The allele sizes were recorded using Gene Marker software V2.2.0 (Soft Genetics, State College, PA, USA).

\subsection{Statistical Analysis}

Average clonal performances were evaluated, and the genotypic and environmental/random effects were estimated by the following linear mixed model, $Y_{i j}=\mu+\beta_{i}+a_{i j}+\varepsilon_{i j}$ using R Software (Version 3.6.1) [38], with Yij as the performance of individual tree $j$ of clone $i, \mu$ as the overall mean, $\mathrm{a}_{\mathrm{ij}}$ as the random clonal value, $\beta_{\mathrm{i}}$ as the fixed effect of block and $\varepsilon_{\mathrm{ij}}$ as the residual variance for each trait. Because each block contained a unique ramet from each clone, the interaction effect of clones and blocks was deleted from the model. The genotypic/clonal values were thus inferred through the relationship $\mathrm{a}_{\mathrm{ij}}=\mathrm{Y}_{\mathrm{ij}}-\mu-\beta_{\mathrm{i}}$, and the variance components were calculated by $\sigma_{Y i j}^{2}=\sigma_{a i}^{2}+\sigma_{\varepsilon}^{2}$, considering the microenvironmental conditions of blocks in the orchard to be identical. $\sigma_{a i^{\prime}}^{2} \sigma_{\varepsilon}^{2}$ and $\sigma_{Y i j}^{2}$ represented the genotypic variance, variance of within plot error, and total phenotypic variance, respectively [39]. Two-way analysis of variance ( $\mathrm{F}$ test) was used to test the significance of growth differences in clones for all phenotypic traits. The clonal repeatability was estimated following [40] to determine the proportion of the total phenotypic variance that was due to the genotypes of clones by $H^{2}=\sigma_{a i}^{2} / \sigma_{Y i j}^{2}$. Using clonal variances, the broad-sense genetic correlation was computed according to Liang et al. [9] by dividing trait covariance values by the square root of the sum of trait variances. The heat map package in R 3.6.1 was used to plot the genetic correlation using all the investigated phenotypic characteristics [41]. To measure the genetic divergence between the collections sites of the cloned genotypes, the formula proposed by Brommer, and Whither [42] was used as shown in the 
following relationship, $Q_{S T}=\sigma_{A B}^{2} / \sigma_{A B}^{2}+2 \sigma_{A W}^{2}$, where $\sigma_{A B}^{2}$ and $\sigma_{A W}^{2}$ were the genotypic variances between and within clones from the selection site, respectively.

Clonal phenotypic performances were standardized by subtracting the mean value and dividing by the standard deviation to construct an individual pairwise genetic distance using the Mahalanobis distance of dissimilarity. The dissimilarity matrix was then used to compare the genetic distances between phenotypic and molecular characteristics [43]. Finally, using clonal values, the clonal rank ordination of all the 110 cloned $P$. koraiensis genotypes was performed using an agglomerative hierarchical clustering (AHC) method [44]. The unweighted pair-group average method with the Pearson correlation coefficient as similarity indices was used to group all the clones that shared similar genotypic values from their phenotypic characteristics using XLSTAT software, (Boston, MA, USA. https://www.xlstst.com). [44].

Genotypic data of clones were recorded by SSR markers (allele sizes) using codominant values. First, clone kinship estimation using the SSR genotypes was done according to the protocol of $\mathrm{Wu}$ et al. [45]. The allele frequency analysis was performed based on the maximum likelihood method using CERVUS software version 3.0.7, (Field Genetics Ltd., London, U.K.), [46] and the range of allele frequency $(\mathrm{Pi})$ and polymorphic information content (PIC) of each locus were computed [47]. Based on the plus tree origin selection sites, the genetic diversity parameters, including the effective number of alleles $(\mathrm{Ne})$, number of different alleles per locus $(\mathrm{Na})$, and Shannon's Information Index (I), were computed according to [48], I $=-1 \times$ Sum (pi $\times$ Ln (pi)), with (pi) being the allele frequencies, and the observed heterozygosity $(\mathrm{Ho})$, expected heterozygosity $(\mathrm{He})$, unbiased expected heterozygosity ( $\mathrm{uHe}$ ), and fixation index (F) were calculated using GenAlEx 6.5.1b2, (Canberra, Australia, biology-assets.anu.edu.au/GenAlEx) [49]. The genetic differentiation $\left(\mathrm{F}_{\mathrm{ST}}\right)$ was retained from the analysis with GenAlEx software to test whether the two collection sites of clones were genetically different and to link genotypic differences to observed phenotypic characteristics.

The Bayesian model of [50] integrated in STRUCTURE 2.3.4 software (Jonathan Pritchard lab, Stanford university, CA, USA) was used to analyze the genetic structure to verify the strength of a clone's genetic relationship (clonal genetic grouping) using 10 independent runs and 5000 Markov Chain Monte Carlo (MCMC) repetitions after a burn-in period, as well as 5000 iterations for each group number of $\mathrm{K}$ that extended from 1 to 10 . The method of utilizing the online tool Structure Harvester [51] and Structure Selector [52] were used to determine the likely number of genetic groups, and the optimum $\mathrm{K}$ value was obtained by the rate of change of the likelihood distribution (mean), as demonstrated by references.

A pairwise comparison of individual genetic distances was performed using Nei's genetic distance method [53] in Power Marker software version 3.25 (Copyright (C) 2019, Informer Technologies, Inc., Los Angeles, CA, USA) [54]. The dissimilarity matrix was then used to construct a dendrogram using the Neighbor-joining method in Power Marker software. The interactive online tool "tree of life, ITOL" (www.itol.embl.de) [55] was used to visualize and edit the tree plot. Furthermore, an analysis of molecular variance (AMOVA) was conducted to determine the extent of the related individual genetic variation to the selected sites of the plus tree of different clones using GenALEx version 6.4.1 [49]. The comparison of the dissimilarity matrices (on phenotypic characteristics and SSR data) was performed using the mantel test in the XLSTAT 2 program 2019.

\section{Results}

\subsection{Phenotypic Variability}

Clone variability and variation parameters in different traits were presented in Table 1. The phenotypic coefficient of variance for all characteristics ranged from $4.44 \%$ in stem straightness degree to $23.54 \%$ in stem volume. The proportion of variance that related to genotypes (clone repeatability) (Table 1) ranged from 0.02 in stem straightness degree to 0.98 in cone width. Traits related to the cone, seed, and nut were more stable, with repeatability values ranging from 0.80 for coat 
thickness to 0.98 for cone width, indicating that the observed differences in fruit characteristics were more related to clone identity than to the environment. These high repeatability values suggest that these traits could serve as an important basis for material selection. The average growth performances of clones was significantly different; furthermore, most of the characteristics showed moderate to very high levels of significant differences $(0.05 \leq p$-value $\leq 0.001)$ based on ANOVA (Table 1$)$, apart from stem straightness degree and cone number, for which the difference was not significant between clones, with $p$-values equal to 0.553 and 0.993 , respectively. Highly significant differences were observed between blocks for some traits, indicating variation in environmental condition in the orchard. Collectively, these results demonstrate the feasibility of using the studied genotypes for classification purposes.

The differentiation analysis on the sites of collection based on the morphological characteristics show that the clones in the two collection sites were slightly different, with a phenotypic differentiation coefficient between $2 \times 10^{-6}$ and 0.1901 for most of the morphological traits. However, some characteristics of the cones and seeds showed moderate to high differentiation coefficients, ranging between 0.4 and 0.9 (Table 1).

Table 1. Descriptive statistics and variation parameters of 110 Pinus koraiensis clones grown in the Naozhi seed orchard.

\begin{tabular}{|c|c|c|c|c|c|c|c|c|c|}
\hline Traits & Units & SV & SS & df & MS & $\mathbf{F}$ & PCV & $\mathrm{H}^{2}$ & $Q_{S T}$ \\
\hline \multirow[t]{2}{*}{ Tree height } & (m) & Clones & 620.899 & 109 & 5.696 & $2.965^{* * *}$ & 8.36 & 0.663 & 0.0236 \\
\hline & & Blocks & 89.767 & 9 & 9.974 & $5.191 * * *$ & & & \\
\hline \multirow{2}{*}{ Basal diameter } & $(\mathrm{cm})$ & Clones & 7287.222 & 109 & 66.855 & $3.981 * * *$ & 9.05 & 0.749 & 0.0761 \\
\hline & & Blocks & 384.485 & 9 & 42.721 & $2.544^{* *}$ & & & \\
\hline \multirow{2}{*}{$\begin{array}{c}\text { Diameter at breast } \\
\text { height }\end{array}$} & $(\mathrm{cm})$ & Clones & 6810.669 & 109 & 62.483 & $4.260^{* * *}$ & 9.3 & 0.765 & 0.0036 \\
\hline & & Blocks & 118.065 & 9 & 13.118 & $0.894^{* * *}$ & & & \\
\hline \multirow[t]{2}{*}{ Diameter at 3-m height } & $(\mathrm{cm})$ & Clones & 6228.944 & 109 & 57.146 & $3.685^{* * *}$ & 9.55 & 0.729 & 0.0258 \\
\hline & & Blocks & 162.950 & 9 & 18.106 & $1.167^{*}$ & & & \\
\hline \multirow[t]{2}{*}{ Stem volume } & (m3) & Clones & 6.985 & 109 & 0.064 & $4.490^{* * *}$ & 23.54 & 0.777 & 0.0003 \\
\hline & & Blocks & 0.254 & 9 & 0.028 & $1.976^{* *}$ & & & \\
\hline \multirow[t]{2}{*}{ Burk thickness } & $(\mathrm{mm})$ & Clones & 542.443 & 109 & 4.977 & $1.976^{* * *}$ & 12.2 & 0.494 & 0.0122 \\
\hline & & Blocks & 159.142 & 9 & 17.682 & $7.020^{* * *}$ & & & \\
\hline \multirow{2}{*}{ Stem straightness degree } & & Clones & 5.469 & 109 & 109 & $2.022 * * *$ & 4.44 & 0.505 & 0.0001 \\
\hline & & Blocks & 8.701 & 9 & 0.967 & $38.963^{* * *}$ & & & \\
\hline \multirow[t]{2}{*}{ Branch angle } & $\left({ }^{\circ}\right)$ & Clones & $114,639.207$ & 109 & 1051.736 & $2.063 * * *$ & 9.18 & 0.515 & 0.6407 \\
\hline & & Blocks & 3209.167 & 9 & 356.574 & $0.699^{\mathrm{N}}$ & & & \\
\hline \multirow[t]{2}{*}{ Crown breath } & (m) & Clones & 77.354 & 109 & 0.710 & $2.168^{* * *}$ & 8.03 & 0.539 & 0.0003 \\
\hline & & Blocks & 46.356 & 9 & 5.151 & $15.738^{* * *}$ & & & \\
\hline \multirow[t]{2}{*}{ Crown height } & (m) & Clones & 601.50 & 109 & 5.52 & $2.72 * * *$ & 10.69 & 0.633 & 0.0076 \\
\hline & & Blocks & 52.15 & 9 & 5.79 & $2.86^{* * *}$ & & & \\
\hline \multirow[t]{2}{*}{ Branch number per node } & & Clones & 94.641 & 109 & 109 & 1.455 ** & 13.01 & 0.313 & 0.0034 \\
\hline & & Blocks & 12.895 & 9 & 1.433 & $2.400 *$ & & & \\
\hline \multirow[t]{2}{*}{ Wood density } & $\left(\mathrm{g} / \mathrm{cm}^{3}\right)$ & Clones & 1.025 & 109 & 0.009 & $1.991^{* * *}$ & 13.20 & 0.498 & $2.00 \times 10^{-5}$ \\
\hline & & Blocks & 0.016 & 9 & 0.008 & $1.644^{\mathrm{N}}$ & & & \\
\hline \multirow[t]{2}{*}{ Fiber length } & $(\mu \mathrm{m})$ & Clones & $281,044,500.967$ & 109 & 2,578,389.917 & $4.664^{* * *}$ & 11.13 & 0.786 & 0.0992 \\
\hline & & Blocks & $2,491,085,275.474$ & 9 & $85,899,492.258$ & $155.372 * * *$ & & & \\
\hline \multirow[t]{2}{*}{ Fiber width } & $(\mu \mathrm{m})$ & Clones & $12,701.725$ & 109 & 116.530 & $2.324 * * *$ & 5.71 & 0.570 & 0.1901 \\
\hline & & Blocks & $57,119.958$ & 9 & 1969.654 & $39.277^{* * *}$ & & & \\
\hline \multirow[t]{2}{*}{ Cone number } & & Clones & 925.100 & 109 & 109 & $0.686^{\mathrm{N}}$ & 17.98 & 0.457 & 0.0183 \\
\hline & & Blocks & 60.502 & 9 & 6.722 & $0.539^{\mathrm{N}}$ & & & \\
\hline \multirow[t]{2}{*}{ Cone length } & $(\mathrm{mm})$ & Clones & $27,1671.646$ & 109 & 2492.400 & $13.650^{* * *}$ & 8.91 & 0.927 & 0.0869 \\
\hline & & Blocks & 6518.537 & 9 & 210.275 & $1.152 *$ & & & \\
\hline \multirow[t]{2}{*}{ Cone width } & $(\mathrm{mm})$ & Clones & $16,5848.289$ & 109 & 1521.544 & $43.426^{* * *}$ & 13.25 & 0.977 & 0.4178 \\
\hline & & Blocks & 1231.719 & 9 & 39.733 & $1.134 *$ & & & \\
\hline \multirow[t]{2}{*}{ Cone weight } & (g) & Clones & 2,370,353.219 & 109 & $21,746.360$ & $10.751^{* * *}$ & 16.04 & 0.907 & 0.9809 \\
\hline & & Blocks & $53,424.308$ & 9 & 1723.365 & $0.852^{\mathrm{N}}$ & & & \\
\hline \multirow[t]{2}{*}{ Layer number } & & Clones & 4149.593 & 109 & 109 & $10.607^{* * *}$ & 11.16 & 0.906 & 0.2264 \\
\hline & & Blocks & 208.822 & 9 & 6.736 & $1.877^{* * *}$ & & & \\
\hline \multirow[t]{2}{*}{ Seed number per cone } & & Clones & $352,729.157$ & 109 & 109 & $5.892 * * *$ & 9.73 & 0.830 & 0.4171 \\
\hline & & Blocks & $46,422.283$ & 9 & 1497.493 & $2.727^{* * *}$ & & & \\
\hline \multirow[t]{2}{*}{ Seed length } & $(\mathrm{mm})$ & Clones & 1510.20 & 109 & 13.86 & $10.87^{* * *}$ & 5.86 & 0.908 & 0.0388 \\
\hline & & Blocks & 191.65 & 9 & 13.69 & $10.74^{* * *}$ & & & \\
\hline \multirow[t]{2}{*}{ Seed width } & $(\mathrm{mm})$ & Clones & 739.32 & 109 & 6.78 & $5.84^{* * *}$ & 6.28 & 0.829 & 0.0059 \\
\hline & & Blocks & 96.10 & 9 & 6.86 & $5.91 * * *$ & & & \\
\hline
\end{tabular}


Table 1. Cont.

\begin{tabular}{|c|c|c|c|c|c|c|c|c|c|}
\hline Traits & Units & SV & sS & $\mathrm{df}$ & MS & $F$ & PCV & $\mathbf{H}^{2}$ & $Q_{S T}$ \\
\hline \multirow[t]{2}{*}{ Seed weight } & (g) & Clones & 20.32 & 109 & 0.19 & $16.37^{* * *}$ & 15.66 & 0.939 & 0.0002 \\
\hline & & Blocks & 2.40 & 9 & 0.17 & $15.07^{* * *}$ & & & \\
\hline \multirow{2}{*}{ Nut length } & $(\mathrm{mm})$ & Clones & 1242.77 & 109 & 11.40 & $12.22 * * *$ & 6.51 & 0.918 & 0.0188 \\
\hline & & Blocks & 126.41 & 9 & 9.03 & $9.68^{* * *}$ & & & \\
\hline \multirow[t]{2}{*}{ Nut width } & $(\mathrm{mm})$ & Clones & 279.18 & 109 & 2.56 & $5.62 * * *$ & 5.84 & 0.822 & 0.0004 \\
\hline & & Blocks & 31.92 & 9 & 2.28 & $5.01 * * *$ & & & \\
\hline \multirow[t]{2}{*}{ Nut weight } & (g) & Clones & 3.55 & 109 & 0.03 & $6.72 * * *$ & 17.17 & 0.851 & $3.00 \times 10^{-5}$ \\
\hline & & Blocks & 0.44 & 9 & 0.03 & $6.50^{* * *}$ & & & \\
\hline \multirow[t]{2}{*}{ Coat thickness } & $(\mathrm{mm})$ & Clones & 6.65 & 109 & 0.06 & $5.04 * * *$ & 6.97 & 0.801 & $2.00 \times 10^{-6}$ \\
\hline & & Blocks & 0.51 & 9 & 0.04 & $3.03^{* * *}$ & & & \\
\hline \multirow[t]{2}{*}{1000 seed weight } & (g) & Clones & $3,082,247.35$ & 109 & $28,277.50$ & $11.47^{* * *}$ & 13.37 & 0.913 & 0.9958 \\
\hline & & Blocks & 6090.76 & 9 & 1015.13 & $0.41^{\mathrm{N}}$ & & & \\
\hline
\end{tabular}

Note: SV, SS, df, MS, PCV,F, $\mathrm{H}^{2}$ and $Q_{S T}$ represent the source of variance, sum square, degrees of freedom, mean square, phenotypic coefficient of variance, F Fisher-Yates coefficients, repeatability and between site genetic divergence respectively. ${ }^{* * *}$ represents a highly significant difference ( $p$-value $\left.\leq 0.001\right),{ }^{* *}$ represents a significant difference $(p$-value $\leq 0.05),{ }^{*}$ represents a significant difference $(p$-value $\leq 0.05)$ and NS indicates no significant difference.

\subsection{Classification Analysis of Phenotypic Characteristics}

Cluster analysis was carried out on phenotypic traits in order to establish clonal ordination based on their performance (Figure 1) and to show the genotypic grouping (Figure S1). The clonal values (genotypic) from each trait were calculated and used to compute the similarity/dissimilarity distance indices from which an AHC method was used to construct a dendrogram with the dissimilarity matrix (Figure 1). Along the axis of individual distribution on the cluster dendrogram, three large groups of clones with similar phenotypic characteristics were detected from the 110 clones containing at least two subgroups. From left to right, the first cluster contained 56 clones, the second contained only seven clones, and the third contained 47 clones. Considering the origin of clones (selection site), all groups contained clones from both sites, showing no phenotypic specificity related to the origin selection site of the clones from the Naozhi forest and the Liaoning Caohe forestland.

The heatmap of correlation also showed three distinct clusters of traits in all the investigated phenotypic characteristics (Figure 2). From left to right, the first cluster was characterized by crown and wood traits; the second cluster by stem traits; and the third by cone-, seed-, and nut-related characteristics.

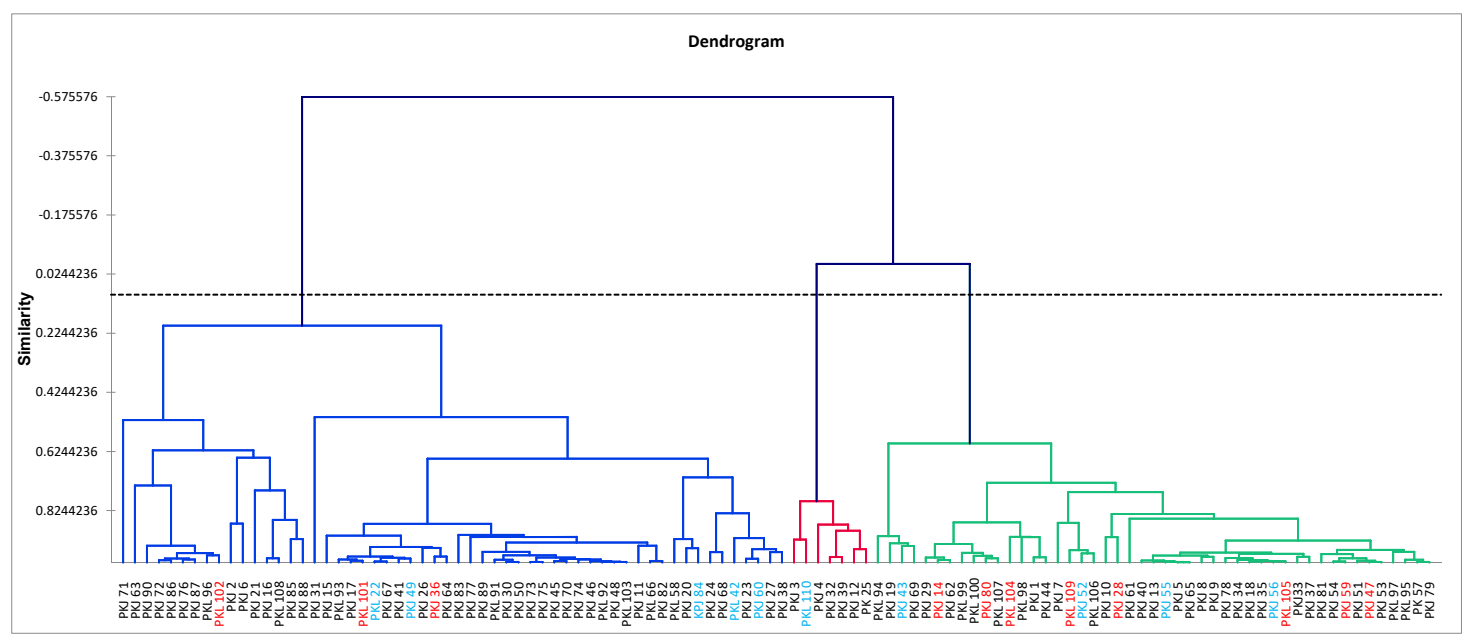

Figure 1. Clustering dendrogram showing cluster patterns of 110 Pinus koraiensis clones grown at the Naozhi orchard using the unweighted pair-group average method with Pearson correlation coefficient of similarity indices on 28 growth, wood, cone, seed, and nut traits. Genotypes in red and blue represent $10 \%$ of clones having exhibited high clonal value in volume and seed weight, respectively. 


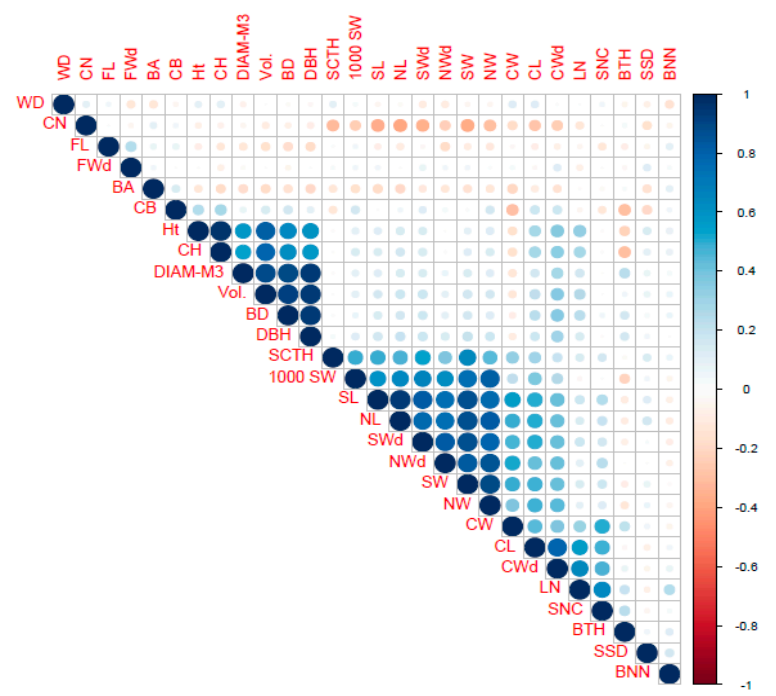

(a)

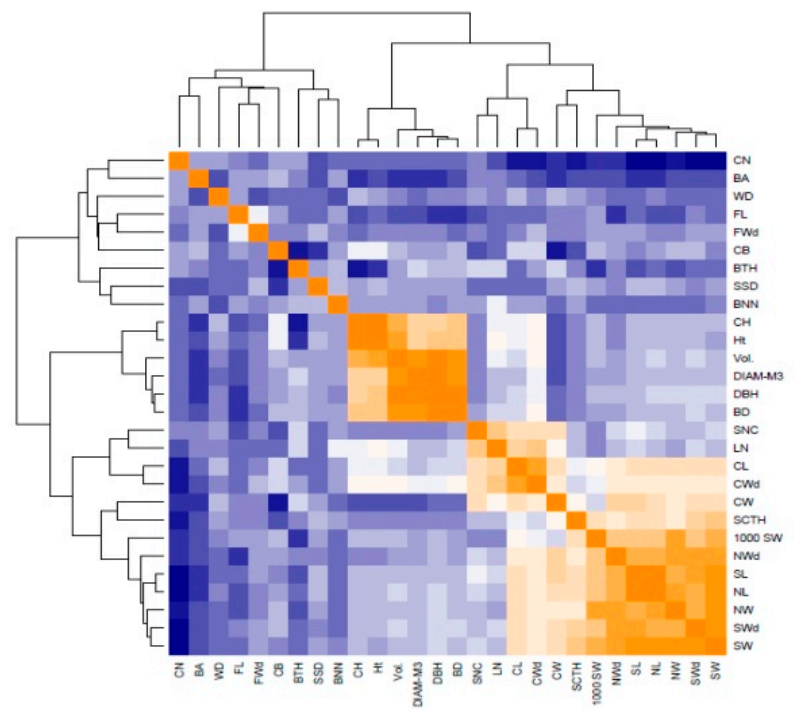

(b)

Figure 2. Correlation analysis of 28 growth, wood, cone, seed, and nut traits of 110 P. koraiensis clones grown at the Naozhi orchard. (a) Significance of correlation levels between traits and (b) clustering dendrogram of the correlated traits. WD: wood density; CN: cone number; FL: fiber length; FWd: fiber width; BA: branch angle; $\mathrm{CB}$ : crown breadth; Ht: tree height; $\mathrm{CH}$ : crown height; DIAM-M3: diameter at 3-m height; BD: basal diameter; DBH: diameter at breast height; SCTH: coat thickness; 1000 SW:1000 seed weight; CW: cone weight; SL:seed length; NL: nut length; SWd: seed width; NWd: nut width; NW: nut weight; SW: seed weight; CW: cone weight; CL: cone length; CWd: cone width; LN: layer number; SNC: seed number per cone; BTH: bark thickness; SSD: stem straightness degree; BNN: branch number per node.

\subsection{Clone Structure and Genetic Diversity}

Sixteen SSR primers were used to analyze the 110 Korean pine clones from the Naozhi orchard. The SSR polymorphism data are given in Table S1 of the supplemental material. The lowest allele frequency range $(\mathrm{Pi})$ was 0.005 , and the highest was 0.764 . The average polymorphic information content (PIC) of the 16 SSR loci was 0.574 (Table 2). The genetic variation parameters of clones are presented in Table 1. The mean number of alleles per locus (Na) was $4.67 \pm 0.43$ and ranged from $2.00 \pm 0.00$ to $9.00 \pm 2.00$. The average number of effective alleles ( $\mathrm{Ne}$ ) was $2.916 \pm 0.18$ and ranged from $1.53 \pm 0.06$ to $4.35 \pm 0.42$. The mean unbiased expected heterozygosity (uHe, $0.63 \pm 0.02)$ and the 
mean expected heterozygosity $(\mathrm{He}, 0.62 \pm 0.02)$ were lower than the mean observed heterozygosity $(\mathrm{Ho}, 0.69 \pm 0.04)$, with a fixation index $(\mathrm{F})$ of $-0.11 \pm 0.03$. The calculated Shannon's Information Index (I) was $1.15 \pm 0.07$. The analysis of molecular variance (AMOVA) revealed that the primary source of genetic variance $(96 \%)$ was within the collection sites of clones, and a small amount of variation (4\%) appeared between the selection sites of clones (Table 3), indicating that there were allele exchanges by genetic flux between the two sites. A weak genetic differentiation among the site of collection $(0.03 \pm 0.01)$ was also indicated by pairwise Fst ranging from 0.001 to 0.077 (Table 2).

Table 2. Diversity statistics of the 16 microsatellite markers on 110 P. koraiensis clones grown at the Naozhi seed orchard.

\begin{tabular}{|c|c|c|c|c|c|c|c|c|}
\hline Locus & $\mathrm{Na}$ & $\mathrm{Ne}$ & I & Ho & $\mathrm{He}$ & uHe & $\mathbf{F}$ & Fst \\
\hline РCP45071 & $7.00 \pm 0.00$ & $4.10 \pm 0.88$ & $1.59 \pm 0.11$ & $0.92 \pm 0.02$ & $0.75 \pm 0.05$ & $0.76 \pm 0.05$ & $-0.24 \pm 0.07$ & 0.042 \\
\hline Pt79951 & $3.00 \pm 1.00$ & $2.02 \pm 0.09$ & $0.75 \pm 0.08$ & $0.58 \pm 0.02$ & $0.51 \pm 0.02$ & $0.51 \pm 0.02$ & $-0.16 \pm 0.09$ & 0.003 \\
\hline 10F/RR & $8.00 \pm 0.00$ & $4.35 \pm 0.42$ & $1.66 \pm 0.08$ & $0.79 \pm 0.11$ & $0.77 \pm 0.02$ & $0.78 \pm 0.03$ & $-0.03 \pm 0.12$ & 0.053 \\
\hline P11 & $3.00 \pm 1.00$ & $1.98 \pm 0.12$ & $0.77 \pm 0.11$ & $0.55 \pm 0.03$ & $0.49 \pm 0.03$ & $0.50 \pm 0.02$ & $-0.11 \pm 0.07$ & 0.002 \\
\hline P25 & $2.00 \pm 0.00$ & $1.98 \pm 0.09$ & $0.69 \pm 0.01$ & $0.55 \pm 0.03$ & $0.49 \pm 0.01$ & $0.50 \pm 0.01$ & $-0.11 \pm 0.01$ & 0.002 \\
\hline P44 & $3.50 \pm 0.50$ & $2.26 \pm 0.24$ & $0.96 \pm 0.02$ & $0.66 \pm 0.14$ & $0.55 \pm 0.05$ & $0.56 \pm 0.05$ & $-0.19 \pm 0.15$ & 0.034 \\
\hline P49 & $4.00 \pm 0.00$ & $3.23 \pm 0.28$ & $1.26 \pm 0.06$ & $0.71 \pm 0.04$ & $0.69 \pm 0.03$ & $0.69 \pm 0.03$ & $-0.04 \pm 0.01$ & 0.034 \\
\hline P60 & $9.00 \pm 1.00$ & $4.37 \pm 0.45$ & $1.75 \pm 0.06$ & $0.92 \pm 0.03$ & $0.77 \pm 0.02$ & $0.78 \pm 0.02$ & $-0.20 \pm 0.08$ & 0.048 \\
\hline P60 & $9.00 \pm 2.00$ & $4.22 \pm 0.15$ & $1.69 \pm 0.01$ & $0.94 \pm 0.04$ & $0.76 \pm 0.01$ & $0.78 \pm 0.02$ & $-0.24 \pm 0.07$ & 0.001 \\
\hline P62 & $3.00 \pm 0.00$ & $2.20 \pm 0.03$ & $0.90 \pm 0.01$ & $0.60 \pm 0.10$ & $0.55 \pm 0.01$ & $0.55 \pm 0.01$ & $-0.10 \pm 0.20$ & 0.020 \\
\hline P63 & $5.00 \pm 0.00$ & $3.25 \pm 0.55$ & $1.32 \pm 0.12$ & $0.81 \pm 0.09$ & $0.68 \pm 0.05$ & $0.69 \pm 0.06$ & $-0.19 \pm 0.04$ & 0.029 \\
\hline P79 & $5.00 \pm 1.00$ & $2.97 \pm 0.64$ & $1.24 \pm 0.25$ & $0.81 \pm 0.06$ & $0.65 \pm 0.07$ & $0.66 \pm 0.07$ & $-0.27 \pm 0.05$ & 0.003 \\
\hline P74 & $2.00 \pm 0.00$ & $1.53 \pm 0.06$ & $0.53 \pm 0.03$ & $0.41 \pm 0.01$ & $0.35 \pm 0.03$ & $0.35 \pm 0.02$ & $-0.20 \pm 0.05$ & 0.024 \\
\hline P82 & $4.00 \pm 1.00$ & $3.19 \pm 0.78$ & $1.29 \pm 0.24$ & $0.69 \pm 0.04$ & $0.67 \pm 0.08$ & $0.68 \pm 0.08$ & $-0.04 \pm 0.07$ & 0.077 \\
\hline P90 & $4.00 \pm 0.00$ & $2.47 \pm 0.20$ & $1.11 \pm 0.05$ & $0.56 \pm 0.11$ & $0.59 \pm 0.03$ & $0.60 \pm 0.03$ & $0.06 \pm 0.13$ & 0.003 \\
\hline P92 & $3.00 \pm 0.00$ & $2.55 \pm 0.27$ & $0.99 \pm 0.07$ & $0.43 \pm 0.23$ & $0.60 \pm 0.04$ & $0.61 \pm 0.05$ & $0.26 \pm 0.43$ & 0.044 \\
\hline Mean & $4.67 \pm 0.43$ & $2.916 \pm 0.18$ & $1.15 \pm 0.07$ & $0.69 \pm 0.04$ & $0.62 \pm 0.02$ & $0.63 \pm 0.02$ & $-0.11 \pm 0.03$ & $0.03 \pm 0.01$ \\
\hline
\end{tabular}

Note: $\mathrm{Na}=\mathrm{No}$. of alleles per locus; $\mathrm{Ne}=\mathrm{No}$. of effective alleles $=1 /\left(\mathrm{Sum}_{\mathrm{pi}}{ }^{2}\right), \mathrm{I}=$ Shannon's Information Index $=-1 *$ Sum ( $\mathrm{pi}^{*}$ Ln (pi)), Ho = Observed Heterozygosity = No. of Hets/N, He = Expected Heterozygosity $=1-$ Sum $\mathrm{pi}^{2}, \mathrm{uHe}=$ Unbiased Expected Heterozygosity $=(2 \mathrm{~N} /(2 \mathrm{~N}-1)) * \mathrm{He}, \mathrm{F}=\mathrm{Fixation}$ Index $=(\mathrm{He}-\mathrm{Ho}) / \mathrm{He}$ $=1-(\mathrm{Ho} / \mathrm{He}), \mathrm{Fst}=(\mathrm{Ht}-\mathrm{Mean} \mathrm{He}) / \mathrm{Ht}$ and $\mathrm{Ht}=$ Total Expected Heterozygosity $=1-\mathrm{Sum}_{\mathrm{mpi}}{ }^{2}$, where tpi is the frequency of the ith allele for the total, and Sum tpi ${ }^{2}$ is the sum of the squared total allele frequencies.

Table 3. Analysis of molecular variance (AMOVA) of 110 P. koraiensis clones grown at the Naozhi seed orchard.

\begin{tabular}{cccccc}
\hline Source & df & \multicolumn{1}{c}{ SS } & MS & Est. Var. & $\%$ \\
\hline Among collection sites & 1 & 19.680 & 19.680 & 0.224 & $4 \%$ \\
Within collection sites & 218 & 1094.361 & 5.020 & 5.020 & $96 \%$ \\
Total & 219 & 1114.041 & - & 5.244 & $100 \%$ \\
\hline
\end{tabular}

\subsection{Cluster Analysis by Molecular Markers}

Genetic structure analysis was performed using STRUCTURE software to check the strength of genetic grouping of the 110 P. koraiensis clone genotypes. The number of subgroupings was not clearly identified from the plot of Ln (probability of data) for K (Figure 3a). However, using the $\Delta \mathrm{K}$ method, three clusters were revealed, corresponding to the highest $\Delta \mathrm{K}$ value found, $\mathrm{K}=3$ (Figure $3 \mathrm{~b}$ ). $\mathrm{A}$ few individual admixtures were observed between clusters, indicating weak differentiation (Figure 3c). The 110 Korean pine genotypes were divided into three clusters (Figure 3c)—Cluster 1 (red) contained 38 individuals, Cluster 2 (green) included 40 individuals, and Cluster 3 (blue) included 32 clone genotypes. Three major groups were also observed on the neighbor-joining clustering dendrogram (Figure 3d) based on Nei's genetic distances on the SSR data. All the clones were mixed in the formed groups, confirming the genetic flux between natural lands of Korean pine. 


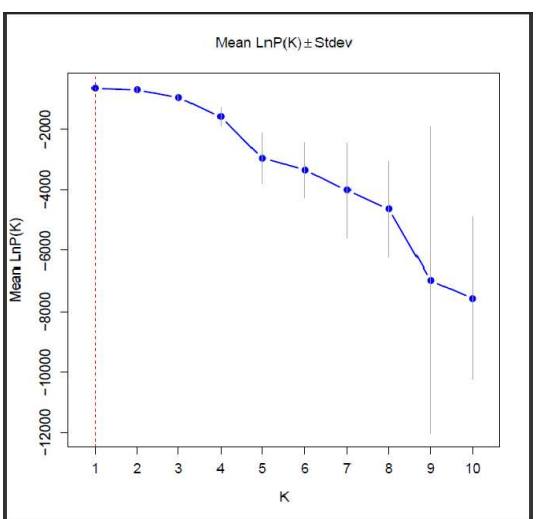

(a)
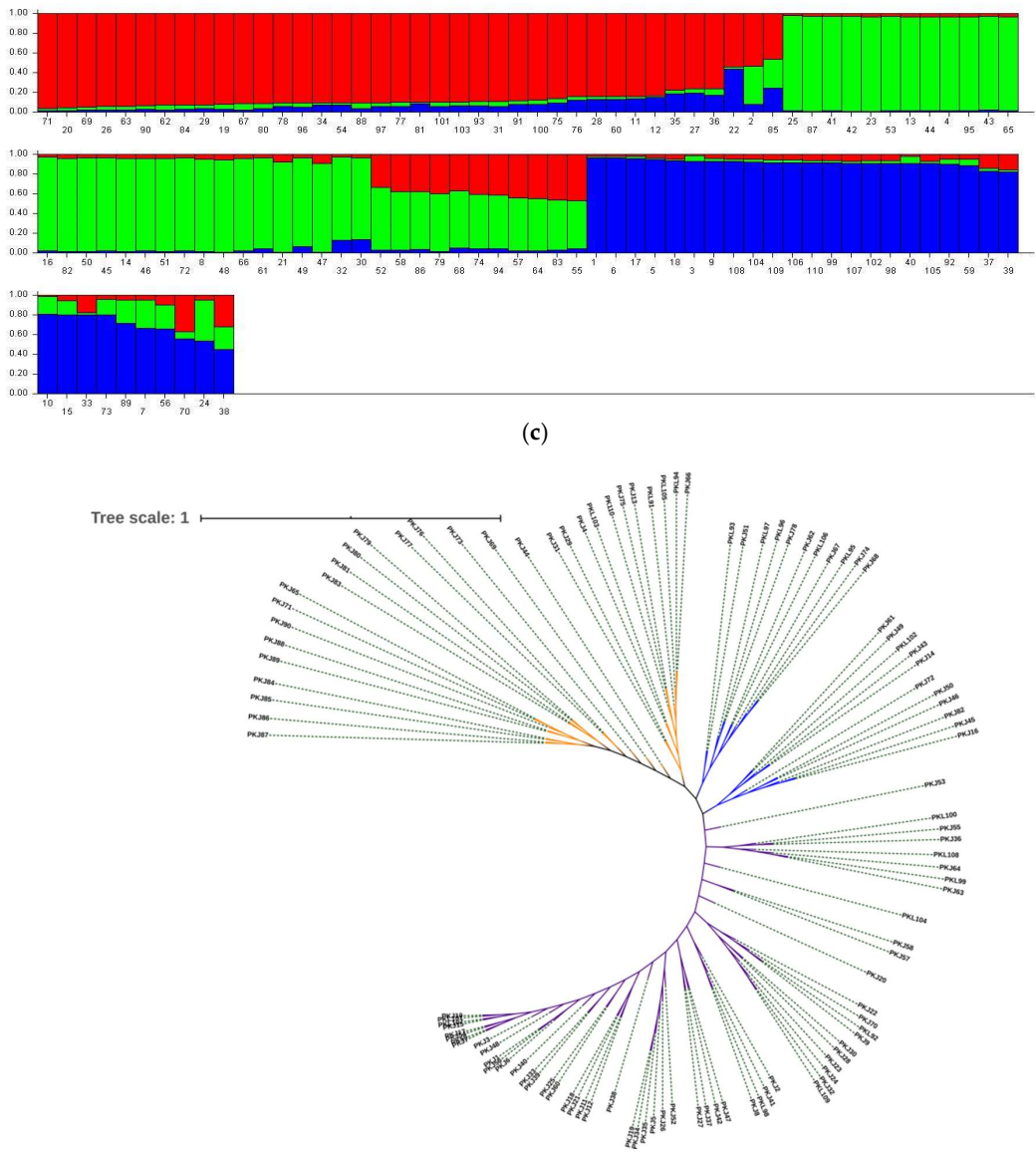

(d)

Figure 3. Genetic structural and cluster analyses of 110 P. koraiensis clones. (a) The probability of the data $\ln \mathrm{P}(\mathrm{D})$ (+SD) against the number of K clusters; (b) $\Delta \mathrm{K}$ values from the mean log-likelihood probabilities inferred clusters $(\mathrm{K})$; (c) Estimated genetic clustering $(\mathrm{k}=3)$ and $(\mathrm{d})$ showed clusters based on Nei's genetic distance. The $x$-axis in (c) indicates the clone's number, and the $y$-axis value shows group membership.

\subsection{Correlation between Phenotypic and Molecular Markers}

To determine the correspondence level between the dissimilarity matrices based on phenotypic characteristics and SSR markers, a Mantel test of correlation was performed. The correlation result is shown in Figure 4. There was a significant positive correlation between the dissimilarity matrices on the phenotypic and genetic distances $\mathrm{r}(\mathrm{A} / \mathrm{B})=0.022,(\alpha=0.05, p$-value $<0.001)$, suggesting that the molecular and phenotypic categorizations of $P$. koraiensis were nearly identical. 


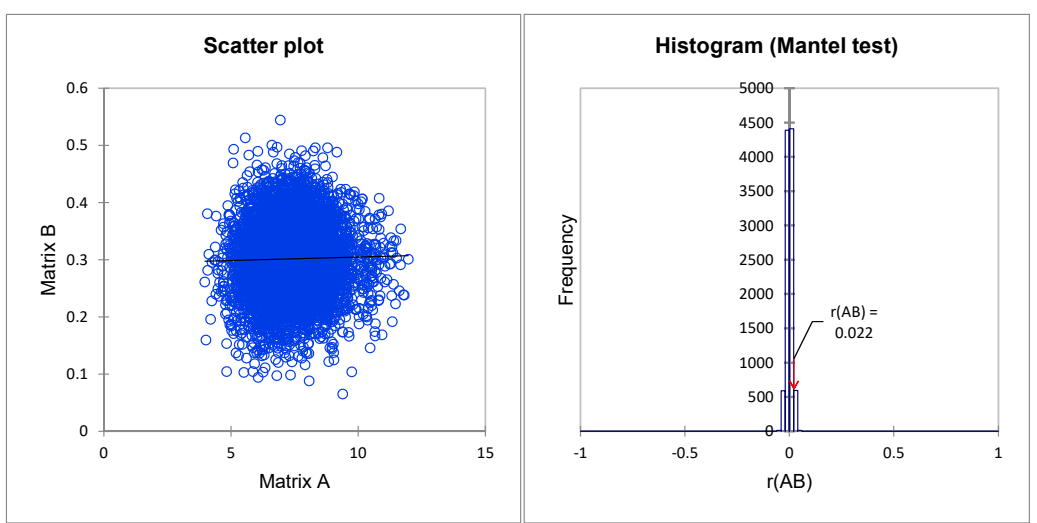

Figure 4. Correlation analysis between dissimilarity matrices of clonal genetic relatedness from 16 SSR markers and clonal genotypic values of 28 phenotypic traits.

\section{Discussion}

\subsection{Clone Variability Based on Phenotypic Characteristics}

In general terms, phenotypic characteristics are considered the basic elements for detecting dissimilarities/similarities between individuals from the same or different tree species [56]. In tree breeding research, growth characteristics (i.e., stem height and diameter) are widely used to select various varieties according to different growing sites in several tree improvement programs [57]. Wood properties, such as fiber dimensions (length and width) and fruit characteristics, are associated with growth traits to assess whether the scope of the tree affects the quality of wood or produced paper [58] and also to determine if the fruit quantity and/or quality are dictated by tree growth size [59]. The present study combined phenotypic and genetic characteristics to assess phenotypic variation and genetic diversity. Preliminary studies showed high phenotypic variation in multiple traits. To highlight the intersection between phenotypic variability and genetic diversity, 28 phenotypic characteristics (11 stem and 17 fruit traits), and 16 microsatellite markers were used in this study.

The mean growth performances showed a significant difference among clones for most growth traits, indicating the effects of clone genotype were significant, and this result was supported by a clonal repeatability greater than $70 \%$ for these characteristics. This result is promising for the selection of P. koraiensis clones. Similar findings were reported on many tree species, indicating that selection based on phenotypic variation results is feasible [60-63]. Considering the extent of phenotypic variation, the clone variability in PCV values (\%) seems to be slightly lower compared to prior P. koraiensis variation studies $[9,10]$; this is likely due to the age difference in Korean pine materials used in each study [61], the genetic properties (clone against families), planting design and different environmental conditions. The material age is an important factor in growth variation of planted trees that share similar environmental conditions, and growth sizes seem to be uniform among mature trees [64].

The genetic variation parameters evaluated in this work on phenotypic traits seem to be higher, especially in fruit-related traits, with repeatability values up to $90 \%$. A previous study of [65] reported heritability values of less than 0.7 in fruit characteristics while investigating 33 years of Korean pine half-sib families. The variation in environmental conditions in the orchard would have influenced the variation, given significant growth differences from subblocks obtained in several growth characteristics. Indeed, with unique ramets for each clone in the subblocks, the effect of the interaction of clones and blocks in the growth model was not taken into account. This could have overestimated the performance of the clones. However, these results retained their value based on the overall assessment of the growth of clones on the whole seed orchard. 


\subsection{Cluster Analysis Based on Phenotypic Traits}

All 110 clones exhibited a strong significant difference in most of the investigated traits. However, the clustering dendrogram (Figure 1) showed three large distinct groups of clones, displaying different high-performance values in different growth traits. Taking into account the trait correlations, three different clusters of characteristic traits were also detected from the clustering dendrogram built according to phenotypes (Figure 2). Since these trees were planted in a randomized design with more or less identical soil and climatic conditions, the differences in growth and phenotypic traits between clones might be related to the genetic properties of the clones [66]. Cluster analysis has been widely used in the classification of plant genetic material. Dendrograms were constructed using morpho-physiological traits for Prunus avium L. [67] and Festuca arundinacea Schreb. [68], along with morphological traits for Medicago sativa L. [68], suggesting that useful information can be obtained from the classification of plant materials.

\subsection{SSR Polymorphism and Clone Genetic Diversity}

Since phenotypic markers are affected by the environment, they are less useful for characterizing neutral genetic diversity to effectively capture the genetic diversity required to maintain a wide genetic base in future breeding programs [69-73]. The use of genetic markers overcame this selection error mostly because genetic markers are not affected by the environment and can be detected at any development stage of the tree [74]. SSR marker techniques have been widely used to detect genetic variation and estimate population genetic diversity and individual relatedness levels in many tree populations. The 110 P. koraiensis clones in this study showed high genetic diversity based on SSR marker analysis. The average number of alleles and effective alleles per locus $(\mathrm{Na}, 4.67 \pm 0.43 ; \mathrm{Ne}$, $2.916 \pm 0.18)$ and the mean $\mathrm{He}(0.62 \pm 0.02)$ and $\mathrm{uHe}(0.63 \pm 0.02)$ were higher compared to the diversity parameters reported for Pinus thunbergii [75]. However, the values determined in this study were higher compared to results reported by [76,77], which analyzed the mating system in a complete P. koraiensis population containing seeds, male and female trees using 14 SSR markers. Our results corroborated previous studies [78,79], which indicated higher genetic diversity in Chinese natural Korean pine populations compared to that of other populations in the Russian region.

The PIC, Shannon's Information Index (I), and Fixation Index (F) were 0.5736 $\pm 0.294,1.15 \pm 0.07$, and $-0.11 \pm 0.03$, respectively, and were comparable to the findings of [16] that analyzed SSR markers. The great genetic diversity observed in P. koraiensis is an essential factor for improving the efficient selection of genotypes that might resist different environmental hazards (climate, parasites, etc.) [80]. Several factors, including the mating system, affect the maintenance of high genetic diversity in tree populations to varying degrees [81-83]. One study [16] demonstrated that the pollen source of P. koraiensis was greatly affected by wind direction during the pollination season. The Fixation Index $(\mathrm{F})$ of $-0.11 \pm 0.03$ that we found in this orchard complex suggested strong inbreeding. Similar results of limited heterozygotes in seed orchard materials have been reported by other workers (e.g., Arnaud-Haond et al. [83]), while other authors have reported a slight excess of heterozygosity (e.g., Nybom [84]).

\subsection{Genetic Structure and Clone Genetic Relatedness}

The genetic structure of tree species is affected by numerous factors, including population size, mating systems, genetic drift, gene flow, seed dispersal, natural selection, and evolutionary history $[19,85]$. The impact of a change in genetic structure can be serious, especially when it affects the mating system or the process of gene flow. Any planting design in a seed orchard is a change to the natural genetic structure and may bring together genetically closed or genetically distant individuals, thus affecting the structure of future generations $[48,86]$. Our analysis of genetic structure showed that the 110 clones formed three genetic groups with a few admixed individuals, indicating weak genetic divergence among clones from the two clone collection sites (Figure 3c). AMOVA results also 
revealed that only $4 \%$ of variation was accounted for among collection sites, while $96 \%$ of genetic variation occurred among clone/within clone collection sites $(P<0.001)$ (Table 3$)$. This finding may be explained by the fact that the two collection sites are located in the southwest region of a large distribution area of Korean pine and benefit from similar propagation conditions. The two sites are $476 \mathrm{~km}$ apart, which appears to be wide enough to prevent an effective gene flow [87] for this wind-pollinated species $[69,88]$. The comparison of both hierarchical-joining cluster results (Figure 1), the Bayesian STRUCTURE (K = 3) bar plot (Figure 3c), and neighbor-joining cluster results (Figure 3d) showed a relative approximation in the interpretation between the genetic relationships and the clone classification dendrogram. A similar observation was previously made [49] in a study that found a parallel trend from the classification of a Salix psammophila populations in both clustering analysis methods.

\subsection{Correlations between Phenotypic and Molecular Markers}

The Mantel test [89], which calculates the association between two distance matrices, is widely used to test the linear or monotonic independence of subjects in two distance matrices [90]. As described previously, the Mantel approach is an appropriate test when the hypothesis is formulated in terms of distance matrices (as is the case with genetic data) [90]. In the present study, the Mantel test was used to compare the clone dissimilarity matrix based on phenotypic characteristics and SSR data. The results showed a weak correlation but a positive significant relationship between the distance matrices (Figure 4). This weak correlation is due to the nature of the data and different calculation approaches in distance matrices [91,92]. A low positive correlation was found between SSR data and morpho-physiological traits of tall fescue accessions [67]. In contrast, this study used the agglomerative hierarchical clustering method to identify clones with similar genotypes and phenotypic characteristics. Three groups were detected in both dendrograms (Figures 1 and 3). The correlation in dissimilarity matrices of both classification methods in this study would result in a large number of investigated phenotypic traits (28 characteristics). Ref. [93] showed that a greater number of phenotypic markers could yield a better representation of genetic distances, especially in a small gene pool with a weak environmental effect [94].

\section{Final Considerations}

The present study focused on the variation in phenotypic traits and genetic relationships that exist among a large number of genotypes from clones from plus trees of $P$. koraiensis, which will be used to improve growth and seed production and to maintain a wide genetic diversity in future breeding programs. All the clones were phenotypically different at moderate to high levels of significance. The phenotypic difference was stronger due to the genetic properties of clones than to the environment and physiological effects. A significant relationship was observed between clone classification based on the phenotypic and genetic distances matrices. The results based on the SSR techniques revealed a high level of genetic diversity in the P. koraiensis clones, which is essential for effective selection regarding the reduced and nearest area in the collection sites and the number of individuals in this study. Three main groups were identified by both genetic and phenotypic data.

Based on this work, growth genotypic values and genetic characteristics of 110 P. koraiensis cloned trees at the Naozhi orchard were determined. The classification dendrogram allows identification of whether selectable clones display similar performances in terms of genotypic/clonal values on the ordination axis that may be done on growth performance-based volume and seed weight. For instance, a $10 \%$ slice of high performing materials, which later would serve as selection objects for wood products or seed qualities, showed relatively low to high similarity coefficients ranging between 0.22 and 0.82 . The different genotype groups allow one to determine whether these potentially selectable materials are genetically near or distant from each other in order to prevent inbreeding, which could impact the genetic properties of seeds that are produced and the long-term future improvement of the species. 
Supplementary Materials: The following are available online at http://www.mdpi.com/2073-4425/11/6/673/s1, Figure S1: Clustering dendrogram showing cluster patterns of 110 Punis koraiensis clones grown at the Naozhi orchard using the unweighted pair-group average method with Mahalonobis coefficient of disimilarity indices on 28 growth, wood, cone, seed and nut traits., Figure S2: Genetic structural and clusters grouping of 110 Punis koraiensis clones based on SSR data using Structure Selector, Table S1: Primer sequences and polymorphism characteristics of SSR markers used to characterize 110 P. koraiensis clones grown at the Naozhi seed orchard.

Author Contributions: X.Z. (Xiyang Zhao) and X.Y. conceived the study and designed the methodology; X.Z. (Xinxin Zhang) and D.K.K. carried out the experiments and helped with data validation; J.W. and L.J. conducted data analysis and prepared the tables and figures; Q.Z., J.W. and J.Z. participated in the investigation, provided resources, and assisted with data curation; D.K.K. prepared the original draft; D.P.K. and X.Z. (Xiyang Zhao) reviewed and edited the manuscript; and X.Z. (Xiyang Zhao). and X.Y. supervised the study, served as project administrators, and acquired funding. All authors have read and agreed to the published version of the manuscript.

Funding: We acknowledge the Forestry Science Technology and Development Project (KJZXSA2019046) and Fundamental Research Funds for the Central Universities (2572017DA02) for support of this research.

Conflicts of Interest: The authors declare no conflict of interest. The funders had no role in the design of the study; the collection, analyses, or interpretation of data; the writing of the manuscript; or the decision to publish the results.

\section{References}

1. Zhang, J.; Zhou, Y.; Zhou, G.; Xiao, C. Composition and structure of Pinus koraiensis mixed forest respond to spatial climatic changes. PLoS ONE 2014, 9, e97192. [CrossRef] [PubMed]

2. Qin, Y.; Xiao, X.; Dong, J.; Zhang, G.; Shimada, M.; Liu, J.; Li, C.; Kou, W.; Moore, B., III. Forest cover maps of China in 2010 from multiple approaches and data sources: PALSAR, Landsat, MODIS, FRA, and NFI. ISPRS J. Photogramm. 2015, 109, 1-16. [CrossRef]

3. Li, C.Z.; Löfgren, K.G. A theory of red pine (Pinus koraiensis) management for both timber and commercial seeds. For. Sci. 2000, 46, 284-290. [CrossRef]

4. Zhang, Z.; Zhang, H.; Yang, C.; Zhang, L.; Du, J.; Jiang, Y. Clonal variations in nutritional components of Pinus koreansis seeds collected from seed orchards in Northeastern China. J. For. Res. 2016, 27, 295-311. [CrossRef]

5. Yu, D.; Zhou, L.; Zhou, W.; Ding, H.; Wang, Q.; Wang, Y.; Wu, X.; Dai, L. Forest management in Northeast China: History, problems, and challenges. J. Environ. Manag. 2011, 48, 1122-1135. [CrossRef]

6. Owari, T.; Tatsumi, S.; Ning, L.; Yin, M. Height growth of Korean pine seedlings planted under strip-cut larch plantations in Northeast China. J. Res. 2015, 2015, 178681. [CrossRef]

7. Sun, H.; Dai, E.; Li, Y.; Xi, W. Climate change and sustainable forestry: A regional perspective from northeast China. For. Chron. 2018, 94, 201-207. [CrossRef]

8. Wang, G.; Ning, Y.; Jin, J.; Zhang, S.; Yi, H. Study on the establishment technique of seed orchard for Korean pine improved generations. J. For. Res. 2000, 28, 68-69.

9. Liang, D.; Ding, C.; Zhao, G.; Leng, W.; Zhang, M.; Zhao, X.; Qu, G. Variation and selection analysis of Pinus koraiensis clones in northeast China. J. For. Res. 2018, 29, 611-622. [CrossRef]

10. Wang, F.; Zhang, Q.; Tian, Y.; Yang, S.; Wang, H.; Wang, L.; Li, Y.; Zhang, P.; Zhao, X. Comprehensive assessment of growth traits and wood properties in half-sib Pinus koraiensis families. Euphytica 2018, 214, 202-217. [CrossRef]

11. Liang, D.; Wang, B.; Song, S.; Wang, J.; Wang, L.; Wang, Q.; Ren, X.; Zhao, X. Analysis of genetic effects on a complete diallel cross test of Pinus koraiensis. Euphytica 2019, 215, 92. [CrossRef]

12. Kaviriri, D.K.; Li, Y.; Zhang, D.; Li, H.; Fan, Z.; Wang, J.; Wang, L.; Wang, Q.; Wang, D.; Chiang, V.L. Clonal variations in cone, seed and nut traits in a Pinus koraiensis seed orchard in Northeast China. J. For. Res. 2020, 1-9. [CrossRef]

13. Man, B.X.; Zhang, L.; Sun, J.Z.; Yuan, H.S.; Sun, J.J.; Wang, X.Y.; Sun, Y.B.; Qiu, L.; Wang, Y.L.; Wang, Y.Z. On plant growth regulator accelerate seed setting earlier of Pinus koraiensis. J. Beihua Univ. (Nat. Sci.) 2012, 13, 329-334.

14. Li, Y.; Liang, L.; Ge, X.J. Development of microsatellite loci for Pinus koraiensis (Pinaceae). Am. J. Bot. 2010, 97, e39-e41. [CrossRef] 
15. Feng, F.J.; Zhao, D.; Sui, X.; Sun, X.Y. Study on mating system of Pinus koraiensis in natural population based on cpSSR technology. In Advanced Materials Research; Trans Tech Publications Ltd.: Bäch SZ, Switzerland, 2011; Volume 183, pp. 700-704. [CrossRef]

16. Du, J.; Zhang, Z.; Zhang, H.; Junhong, T. EST-SSR marker development and transcriptome sequencing analysis of different tissues of Korean pine (Pinus koraiensis Sieb. et Zucc.). Biotechnol. Biotechnol. Equip. 2017, 31, 679-689. [CrossRef]

17. Atangana, A.R.; Beaulieu, J.; Khasa, D.P. Wild genetic diversity preservation in a small-sized first generation breeding population of Allanblackia floribunda (Clusiaceae). Tree Genet. Genomes 2010, 6, 127-136. [CrossRef]

18. Sui, X.; Feng, F.; Zhao, D.; Xing, M.; Sun, X.; Han, S.; Li, M. Mating system patterns of natural populations of Pinus koraiensis along its post-glacial colonization route in northeastern China. Genet. Mol. Res. 2015, 14, 4113-4124. [CrossRef]

19. Porth, I.; El-kassaby, Y. Assessment of the genetic diversity in forest tree populations using molecular markers. Diversity 2014, 6, 283-295. [CrossRef]

20. Lefort-Buson, M.; Hebert, Y.; Damerval, C. Tools for assessing genetic and phenotypic diversity. Agronomy 1988, 8, 173-178. (In French) [CrossRef]

21. Rezende, G.D.S.P.; de Resende, M.D.V.; de Assis, T.F. Eucalyptus Breeding for Clonal Forestry. In Challenges and Opportunities for the World's Forests in the 21st Century; Fenning, T., Ed.; Springer: Berlin/Heidelberg, Germany, 2014; Forestry Sciences Vol. 81; pp. 393-424.

22. Schaberg, P.G.; Dehayes, D.H.; Hawley, G.J.; Nijensohn, S.E. Anthropogenic alterations of genetic diversity within tree populations: Implications for forest ecosystem resilience. For. Ecol. Manag. 2008, 256, 855-862. [CrossRef]

23. Chan, W.Y.; Hoffmann, A.A.; Van Oppen, M.J. Hybridization as a conservation management tool. Conserv. Lett. 2019, 12, e12652. [CrossRef]

24. Namkoong, G.; Kang, H.C.; Brouard, J.S. Tree Breeding: Principles and Strategies, 1st ed.; Springer Science and Business Media: New York, NY, USA, 2012; Volume 11, pp. 37-111.

25. Meyer, R.C.; Törjék, O.; Becher, M.; Altmann, T. Heterosis of biomass production in Arabidopsis. Establishment during early development. Plant. Physiol. 2004, 134, 1813-1823. [CrossRef] [PubMed]

26. Birchler, J.A.; Auger, D.L.; Riddle, N.C. In search of the molecular basis of heterosis. Plant Cell 2003, 15, 2236-2239. [CrossRef] [PubMed]

27. Šijačić-Nikolić, M.; Isajev, V. Assesment of heterotic effect in Serbian spruce hybrid combination. Genetika 2004, 36, 257-263. [CrossRef]

28. Lynch, M.; Ritland, K. Estimation of pairwise relatedness with molecular markers. Genetics 1999, 152, 1753-1766. [PubMed]

29. Hardy, O.J. Estimation of pairwise relatedness between individuals and characterization of isolation-by-distance processes using dominant genetic markers. Mol. Ecol. 2003, 12, 1577-1588. [CrossRef]

30. Oliveira, E.J.; Pádua, J.G.; Zucchi, M.I.; Vencovsky, R.; Vieira, M.L.C. Origin, evolution and genome distribution of microsatellites. Genet. Mol. Biol. 2006, 29, 294-307. [CrossRef]

31. Xu, Z.; Yu, G.; Zhang, X.; He, N.; Wang, Q.; Wang, S.; Xu, X.; Wang, R.; Zhao, N. Biogeographical patterns of soil microbial community as influenced by soil characteristics and climate across Chinese forest biomes. Appl. Soil Ecol. 2018, 124, 298-305. [CrossRef]

32. Zhu, B.; Wang, X.; Fang, J.; Piao, S.; Shen, H.; Zhao, S.; Peng, C. Altitudinal changes in carbon storage of temperate forests on Mt Changbai, Northeast China. J. Plant Res. 2010, 123, 439-452. [CrossRef]

33. Zhao, X.; Bian, X.; Liu, M.; Li, Z.; Li, Y.; Zheng, M.; Teng, W.; Jiang, J.; Liu, G. Analysis of genetic effects on a complete diallel cross test of Betula platyphylla. Euphytica 2014, 200, 221-229. [CrossRef]

34. Louppe, D. Forest estimate. In Tropical Forester Memento; Editions Quae: Versailles Cedex, France, 2015. (In French)

35. Yin, S.; Xiao, Z.; Zhao, G.; Zhao, X.; Sun, X.; Zhang, Y.; Wang, F.; Li, S.; Zhao, X.; Qu, G.Z. Variation analyses of growth and wood properties of Larix olgensis clones in China. J. For. Res. 2017, 28, 687-697. [CrossRef]

36. Allen, G.; Flores-vergara, M.; Krasynanski, S.; Kumar, S.; Thompson, W. A modified protocol for rapid DNA isolation from plant tissues using cetyltrimethylammonium bromide. Nat. Protoc. 2006, 1, 2320-2325. [CrossRef] [PubMed]

37. Zhang, Z.; Zhang, H.; Mo, C.; Zhang, L. SSR analysis of Pinus koraiensis transcriptome and development of EST-SSR markers. For. Sci. 2015, 51, 114-120. (In Chinese) 
38. Fox, J.; Bouchet-Valat, M.; Andronic, L.; Ash, M.; Boye, T.; Calza, S.; Chang, A.; Grosjean, P.; Heiberger, R.; Pour, K.K. Package 'Rcmdr'. 2018. Available online: http://cran.ma.imperial.ac.uk/web/packages/Rcmdr/ Rcmdr.pdf (accessed on 14 April 2020).

39. Li, Y.; Suontama, M.; Burdon, R.D.; Dungey, H.S. Genotype by environment interactions in forest tree breeding: Review of methodology and perspectives on research and application. Tree Genet. Genomes 2017, 13, 60-78. [CrossRef]

40. Zhou, L.; Chen, Z.; Lundqvist, S.O.; Olsson, L.; Grahn, T.; Karlsson, B.; Wu, H.X.; García-GIL, M.R. Genetic analysis of wood quality traits in Norway spruce open-pollinated progenies and their parent plus trees at clonal archives and the evaluation of phenotypic selection of plus trees. Can. J. For. Res. 2019, 49, 810-818. [CrossRef]

41. Zhao, S.; Guo, Y.; Sheng, Q.; Shyr, Y. Heatmap3: An improved heatmap package with more powerful and convenient features. BMC Bioinform. 2014, 15, 16. [CrossRef]

42. Brommer, J. Whither PST? The approximation of QST by PST in evolutionary and conservation biology. J. Evol. Biol. 2011, 24, 1160-1168. [CrossRef]

43. Junior, P.C.; Ikeda, A.C.; Schuhli, G.S.; Silva, L.D.; Higa, A.R. Repeatability and genetic dissimilarity using biometric characteristics of black wattle seeds. Adv. For. Sci. 2018, 5, 333-337.

44. Vidal, N.P.; Manful, C.F.; Pham, T.H.; Stewart, P.; Keough, D.; Thomas, R. The use of XLSTAT in conducting principal component analysis (PCA) when evaluating the relationships between sensory and quality attributes in grilled foods. MethodsX 2020, 7, 100835. [CrossRef]

45. Kalinowski, S.T.; Taper, M.L.; Marshall, T.C. Revising how the computer program CERVUS accommodates genotyping error increases success in paternity assignment. Mol. Ecol. 2007, 16, 1099-1106. [CrossRef]

46. Manter, D.K.; Delgado, J.A.; Holm, D.G.; Stong, R.A. Pyrosequencing reveals a highly diverse and cultivar-specific bacterial endophyte community in potato roots. Microb. Ecol. 2010, 60, 157-166. [CrossRef]

47. Hosking, L.; Lumsden, S.; Lewis, K.; Yeo, A.; Mccarthy, L.; Bansal, A.; Riley, J.; Purvis, I.; Xu, C.F. Detection of genotyping errors by Hardy-Weinberg equilibrium testing. Eur. J. Hum. Genet. 2004, 12, 395-399. [CrossRef]

48. Wu, F.Q.; Shen, S.K.; Zhang, X.J.; Wang, Y.H.; Sun, W.B. Genetic diversity and population structure of an extremely endangered species: The world's largest Rhododendron. Aob Plants 2015, 7, 9. [CrossRef] [PubMed]

49. Peakall, R.; Smousse, P.E. GeneAlEx 6.5: Genetics analysis in Excel. Population genetics software for teaching and research- an update. Bioinformatics 2012, 28, 2537-2539. [CrossRef] [PubMed]

50. Porras-Hurtado, L.; Ruiz, Y.; Santos, C.; Phillips, C.; Carracedo, Á.; Lareu, M. An overview of STRUCTURE: Applications, parameter settings, and supporting software. Front. Genet. 2013, 4, 98. [CrossRef] [PubMed]

51. Evanno, G.; Regnaut, S.; Goudet, J. Detecting the number of clusters of individuals using the software STRUCTURE: A simulation study. Mol. Ecol. 2005, 14, 2611-2620. [CrossRef] [PubMed]

52. Li, Y.L.; Liu, J.X. StructureSelector: A web based software to select and visualize the optimal number of clusters using multiple methods. Mol. Ecol. Resour. 2018, 18, 176-177. [CrossRef] [PubMed]

53. Nei, M.; Takezaki, N. Estimation of genetic distances and phylogenetic trees from DNA analysis. In Proceedings of the 5th World Congress on Genetics Applied to Livestock Production; The Pennsylvania State University: State College, PA, USA, 1983; p. 16802.

54. Liu, K.; Muse, S.V. PowerMarker: An integrated analysis environment for genetic marker analysis. Bioinformatics 2005, 21, 2128-2129. [CrossRef] [PubMed]

55. Letunic, I.; Bork, P. Interactive tree of life (iTOL) v3: An online tool for the display and annotation of phylogenetic and other trees. Nucleic Acids Res. 2016, 44, W242-W245. [CrossRef] [PubMed]

56. Rédei, K.; Keserû, Z.; Csiha, I.; Rásó, J.; Bakti, B.; Takács, M. Improvement of black locust (Robinia pseudoacacia L.) growing under marginal site conditions in Hungary: Case studies. Acta Agrar. Debr. 2018, 30, 129-133. [CrossRef]

57. Van Leeuwen, M.; Hilker, T.; Coops, N.C.; Frazer, G.; Wulder, M.A.; Newnham, G.J.; Culvenor, D.S. Assessment of standing wood and fiber quality using ground and airborne laser scanning: A review. For. Ecol. Manag. 2011, 261, 1467-1478. [CrossRef]

58. Yang, H.; Zhang, R.; Jin, G.; Feng, Z.; Zhou, Z. Assessing the genetic diversity and genealogical reconstruction of cypress (Cupressus funebris Endl.) breeding parents using SSR markers. Forests 2016, 7, 160. [CrossRef] 
59. Hao, L.; Zhang, G.; Lu, D.; Hu, J.; Jia, H. Analysis of the genetic diversity and population structure of Salix psammophila based on phenotypic traits and simple sequence repeat markers. PeerJ 2019, 7, e6419. [CrossRef] [PubMed]

60. West-Eberhard, M.J. Developmental plasticity and the origin of species differences. PNAS 2005, 102 (Suppl. 1), 6543-6549. [CrossRef]

61. Xiao, Y.; Ma, W.; Lu, N.; Wang, Z.; Wang, N.; Zhai, W.; Kong, L.; Qu, G.; Wang, Q.; Wang, J. Genetic variation of growth traits and genotype-by-environment interactions in clones of Catalpa bungei and Catalpa fargesii $\mathrm{f}$. duclouxii. Forests 2019, 10, 57. [CrossRef]

62. Matsushita, M.; Takata, K.; Hitsuma, G.; Yagihashi, T.; Noguchi, M.; Shibata, M.; Masaki, T. A novel growth model evaluating age-size effect on long-term trends in tree growth. Funct. Ecol. 2015, 29, 1250-1259. [CrossRef]

63. Yang, H.; Weng, Q.; Li, F.; Zhou, C.; Li, M.; Chen, S.; Ji, H.; Gan, S. Genotypic variation and genotype-by-environment interactions in growth and wood properties in a cloned Eucalyptus urophylla $\times E$. tereticornis family in Southern China. For. Sci. 2018, 64, 225-232. [CrossRef]

64. Kenis, K.; Keulemans, J. Study of tree architecture of apple (Malus $\times$ domestica Borkh.) by QTL analysis of growth traits. Mol. Breed. 2007, 19, 193-208. [CrossRef]

65. Kaviriri, D.K.; Liu, X.; Fan, Z.; Wang, J.; Wang, Q.; Wang, L.; Wang, L.; Khasa, D.; Zhao, X. Genetic Variation in Growth and Cone Traits of Pinus Koraiensis Half-Sib Families in Northeast China. Phyton 2020, 89, 57-69. [CrossRef]

66. Cheng, X.; Xie, H.; Zhang, L.; Wang, M.; Li, C.; Yu, M.; He, Z. A comparative study of growth and leaf trait variation in twenty Cornus wilsoniana W. families in southeastern China. iForest 2017, 10, 759-765. [CrossRef]

67. Hamrick, J.L.; Milton, J.; Linhart, Y.B. Levels of genetic variation in trees: Influence of life history characteristics. In General Technical Report PSW-GTR-48; Pacific Southwest Forest and Range Exp. Stn, Forest Service, US Department of Agriculture: Berkeley, CA, USA, 1981; Volume 48, pp. 35-41.

68. Nicotra, A.B.; Chazdon, R.L.; Schlichting, C.D. Patterns of genotypic variation and phenotypic plasticity of light response in two tropical Piper (Piperaceae) species. Am. J. Bot. 1997, 84, 1542-1552. [CrossRef] [PubMed]

69. Ganopoulos, I.; Moysiadis, T.; Xanthopoulou, A.; Ganopoulou, M.; Avramidou, E.; Aravanopoulos, F.A.; Tani, E.; Madesis, P.; Tsaftaris, A.; Kazantzis, K. Diversity of morpho-physiological traits in worldwide sweet cherry cultivars of GeneBank collection using multivariate analysis. Sci. Hortic. 2015, 197, 381-391. [CrossRef]

70. Volk, G.M.; Henk, A.D.; Richards, C.M. Genetic diversity among US garlic clones as detected using AFLP methods. J. Am. Soc. Hortic. Sci. 2004, 129, 559-569. [CrossRef]

71. Sun, X.; Xie, Y.; Bi, Y.; Liu, J.; Amombo, E.; Hu, T.; Fu, J. Comparative study of diversity based on heat tolerant-related morpho-physiological traits and molecular markers in tall fescue accessions. Sci. Rep. 2015, 5, 18213. [CrossRef] [PubMed]

72. Cholastova, T.; Knotova, D. Using morphological and microsatellite (SSR) markers to assess the genetic diversity in Alfalfa (Medicago sativa L.). Int. J. Biol. Biomol. Agric. Food Biotechnol. Eng. 2012, 69, 856-862.

73. Lande, R.; Thompson, R. Efficiency of marker-assisted selection in the improvement of quantitative traits. Genetics 1990, 124, 743-756.

74. Stinchcombe, J.R.; Rutter, M.T.; Burdick, D.S.; Tiffin, P.; Rausher, M.D.; Mauricio, R. Testing for environmentally induced bias in phenotypic estimates of natural selection: Theory and practice. Am. Nat. 2002, 160, 511-523. [CrossRef]

75. Kim, Z.; Lee, S.; Hwang, J. Genetic diversity and structure of natural populations of Pinus thunbergii in Korea. Silvae Genet. 1997, 46, 120-123.

76. Yu, J.-H.; Chen, C.-M.; Tang, Z.-H.; Yuan, S.-S.; Wang, C.-J.; Zu, Y.-G. Isolation and characterization of 13 novel polymorphic microsatellite markers for Pinus koraiensis (Pinaceae). Am. J. Bot. 2012, 99, e421-e424. [CrossRef]

77. Yun, J.; Juan, Z.; Ying, W.; Wei-Bing, F.; Gui-Fang, Z.; Zhong-Hu, L. Effects of geological and environmental events on the diversity and genetic divergence of four closely related Pines: Pinus koraiensis, P. armandii, P. griffithii, and P. pumila. Front. Plant. Sci. 2018, 9, 1264.

78. Feng, F.J.; Sui, X.; Chen, M.M.; Zhao, D.; Han, H.J.; Li, M.H. Mode of pollen spread in clonal seed orchard of Pinus koraiensis. J. Biophys. Chem. 2010, 1, 33-39. [CrossRef] 
79. Potenko, V. Genetic diversity and mating system of Korean pine in Russia. In Breeding and Genetic Resources of Five-Needle Pines: Growth, Adaptability and Pest Resistance; USDA Forest Service Proceedings RMRS-P-32; US Department of Agriculture, Forest Service, Rocky Mountain Research Station: Fort Collins, CO, USA, 2004; p. 11.

80. Potenko, V.; Velikov, A. Genetic diversity and differentiation of natural populations of Pinus koraiensis (Sieb. et Zucc.) in Russia. Silvae Genet. 1998, 47, 202-207.

81. Feng, F.J.; Han, S.J.; Wang, H.M. Genetic diversity and genetic differentiation of natural Pinus koraiensis population. J. Res. 2006, 17, 21-24. [CrossRef]

82. Arnaud-Haond, S.; Teixeira, S.; Massa, S.I.; Billot, C.; Saenger, P.; Coupland, G.; Duarte, C.M.; Serrao, E. Genetic structure at range edge: Low diversity and high inbreeding in Southeast Asian mangrove (Avicennia marina) populations. Mol. Ecol. 2006, 15, 3515-3525. [CrossRef] [PubMed]

83. Ellstrand, N.C. Current knowledge of gene flow in plants: Implications for transgene flow. Philosophical Transactions of the Royal Society of London. Ser. B Biol. Sci. 2003, 358, 1163-1170. [CrossRef]

84. Nybom, H. Comparison of different nuclear DNA markers for estimating intraspecific genetic diversity in plants. Mol. Ecol. 2004, 13, 1143-1155. [CrossRef] [PubMed]

85. Leimu, R.; Mutikainen, P.; Koricheva, J.; Fischer, M. How general are positive relationships between plant population size, fitness and genetic variation? J. Ecol. 2006, 94, 942-952. [CrossRef]

86. Suwarni, E.; Omondi, S.; Dancik, B.; Khasa, D. Estimation of pollen contamination and mating system in Pinus merkusii seedling seed orchard using allozyme markers. J. Trop. Sci. 2018, 30, 95-105.

87. Lowe, A.; Boshier, D.; Ward, M.; Bacles, C.; Navarro, C. Genetic resource impacts of habitat loss and degradation; reconciling empirical evidence and predicted theory for neotropical trees. Heredity 2005, 95, 255-273. [CrossRef]

88. Kremer, A.; Ronce, O.; Robledo-Arnuncio, J.J.; Guillaume, F.; Bohrer, G.; Nathan, R.; Bridle, J.R.; Gomulkiewicz, R.; Klein, E.K.; Ritland, K. Long-distance gene flow and adaptation of forest trees to rapid climate change. Ecol. Lett. 2012, 15, 378-392. [CrossRef]

89. Mantel, N. The detection of disease clustering and a generalized regression approach. Cancer Res. 1967, 27, 209-220. [PubMed]

90. Legendre, P.; Fortin, M.J. Comparison of the Mantel test and alternative approaches for detecting complex multivariate relationships in the spatial analysis of genetic data. Mol. Ecol. Resour. 2010, 10, 831-844. [CrossRef] [PubMed]

91. Franco, J.; Crossa, J.; Ribaut, J.; Bertran, J.; Warburton, M.; Khairallah, M. A method for combining molecular markers and phenotypic attributes for classifying plant genotypes. Theor. Appl. Genet. 2001, 103, 944-952. [CrossRef]

92. Corrado, G.; La Mura, M.; Ambrosino, O.; Pugliano, G.; Varricchio, P.; Rao, R. Relationships of Campanian olive cultivars: Comparative analysis of molecular and phenotypic data. Genome 2009, 52, 692-700. [CrossRef] [PubMed]

93. Roldán-Ruiz, I.; Van Euwijk, F.; Gilliland, T.; Dubreuil, P.; Dillmann, C.; Lallemand, J.; De Loose, M.; Baril, C. A comparative study of molecular and morphological methods of describing relationships between perennial ryegrass (Lolium perenne L.) varieties. Theor. Appl. Genet. 2001, 103, 1138-1150. [CrossRef]

94. Avval, S.E. Assessing polymorphism information content (PIC) using SSR molecular markers on local species of Citrullus colocynthis. Case study: Iran, Sistan-Balouchestan province. J. Mol. Biol. Res. 2017, 7, 42-49. [CrossRef]

(C) 2020 by the authors. Licensee MDPI, Basel, Switzerland. This article is an open access article distributed under the terms and conditions of the Creative Commons Attribution (CC BY) license (http://creativecommons.org/licenses/by/4.0/). 